\title{
ANTA-BRASILEIRA - Tapirus terrestris - Linnaeus, 1758, (Perissodactyla, taperidae): ANATOMIA ÓSSEA E MUSCULAR DA PERNA E PÉ
}

Tapir - Tapirus terrestris - Linnaeus, 1758, (Perissodactyla, taperidae): bone and muscle anatomy of the leg and foot

Tapir - Tapirus terrestris - Linnaeus, 1758, (Perissodactyla, taperidae): anatomie osseuse et musculaire de la jambe et du pied

\section{Daniela Cristina Silva Borges ${ }^{* 1}$, Saulo Gonçalves Pereira ${ }^{1}$ Matheus Destro Rosa Ferreira ${ }^{2}$,} André Luiz Quagliatto Santos ${ }^{2}$

${ }^{1}$ Universidade Federal de Uberlândia, LAPAS, Uberlândia, Brasil e Faculdade Patos de Minas, FPM, Patos de Minas, Brasil.

${ }^{2}$ Universidade Federal de Uberlândia, LAPAS, Uberlândia, Brasil

* Correspondência: LAPAS - UFU - Laboratório de Estudo e Pesquisa em Animais Silvestres. Rua Piauí S/N, B. Umuarama - Uberlândia MG., Brasil. CEP: CEP: 38405-314.

e-maildanybio@hotmail.com.

\section{Artigo recebido em 14/03/2020 aprovado em 11/06/2020 publicado em 09/03/2021.}

\section{RESUMO}

A espécie Tapirus terrestris, conhecida como anta brasileira, é um mamífero da ordem Perissodactyla; a única dessa ordem que ocorre de forma endêmica no Brasil é considerada a maior dos mamíferos brasileiros. Existem poucos estudos relacionados à morfologia da anta, sendo assim, com o intuito de fornecer mais dados anatômicos sobre a espécie, teve-se por objetivo com o presente trabalho descrever os ossos e os músculos da perna e pé de $T$. terrestris. Foram utilizados quatro exemplares de T. terrestris (Linnaeus, 1978) fixados em formaldeído a 10\%. Para a descrição osteológica as peças foram radiografadas e os ossos macerados, limpos, secos, identificados e descritos. Para a descrição muscular, os músculos foram dissecados, segundo as técnicas usuais em anatomia macroscópica, identificados e descritos. O esqueleto da perna de T. terrestris é constituído pelos ossos tíbia e fíbula, o pé composto por três partes sendo o tarso, metatarso e falanges. Os músculos que compõe a perna e o pé são o gastrocnêmio, sóleo, flexor digital superficial, flexor digital profundo, tibial cranial, fibular terceiro, extensor digital longo, extensor digital lateral, poplíteo, interósseos e lumbricais. A perna e pé de T. terrestris possuem características osteológicas e musculares semelhantes à dos equinos, entretanto, algumas diferenças morfológicas são evidenciadas.

Palavras-chave: Morfologia, osteologia, miologia anta.

\section{ABSTRACT}

The species Tapirus terrestris, known as Brazilian tapir, is a mammal of the Perissodactyla order, the only which occurs with an endemic form in Brazil and is considered the one of the largest Brazilian mammals. There are few studies related to the tapir morphology, so to provide more anatomical data about this species, the present study aimed to describe the bones and muscles of the leg and foot in T. terrestris. We used four specimens of T. terrestris (Linnaeus, 1978), fixed in formaldehyde 10\%. For osteological description the anatomical specimens were radiographed and the bones macerated, cleaned, dried, identified and described to muscular description, the muscles were dissected according to the usual techniques in gross anatomy, identified and described. The skeleton of T. terrestris leg consists in tibia and fibula bones, the foot consists of three parts, they are the tarsus, metatarsus and phalanges. The muscles that form the leg and foot are the gastrocnemius, soleus, superficial digital flexor, digital flexor, cranial tibial, fibular third, long digital extensor, lateral digital extensor, popliteal, interosseous and lumbricais. The leg and foot of T. terrestris have osteological and muscular characteristics similar to equines, however, some morfological differences are evident.

Keywords: Morphology, osteology, myology, tapir. 


\section{RESUMEN}

L'espèce Tapirus terrestris, connue sous le nom de tapir brésilien, est un mammifère de l'ordre des Perissodactyla, le seul qui existe avec une forme endémique au Brésil et est considéré comme l'un des plus grands mammifères brésiliens. Il existe peu d'études liées à la morphologie du tapir, afin de fournir plus de données anatomiques sur cette espèce, la présente étude visait à décrire les os et les muscles de la jambe et du pied chez T. terrestris. Nous avons utilisé quatre spécimens de T. terrestris (Linnaeus, 1978), fixés dans du formaldéhyde à 10\%. Pour la description ostéologique, les spécimens anatomiques ont été radiographiés et les os macérés, nettoyés, séchés, identifiés et décrits Pour la description musculaire, les muscles ont été disséqués selon les techniques habituelles en anatomie générale, identifiées et décrites. Le squelette de la jambe de T. terrestris se compose d'os de tibia et de péroné, le pied se compose de trois parties, ce sont le tarse, le métatarse et les phalanges. Les muscles qui forment la jambe et le pied sont le gastrocnémien, le soléaire, le fléchisseur numérique superficiel, le fléchisseur numérique, le tibial crânien, le troisième fibulaire, le long extenseur numérique, l'extenseur numérique latéral, poplité, interosseux et lumbricais. La jambe et le pied de T. terrestris ont des caractéristiques ostéologiques et musculaires similaires à celles des équidés, cependant, certaines différences morfologiques sont évidentes.

Descriptores: Morphologie, ostéologie, myologie tapir

\section{INTRODUÇÃO}

Os ungulados são compostos pelas ordens Artiodactyla e Perissodactyla. A ordem Perissodactyla é um grupo cujos representantes apresentam dedos ímpares, sendo que o digito III é sempre o eixo (mesaxonia) e o mais desenvolvido de todos (PauloCouto, 1979), evolutivamente com o passar do tempo ocorreu a redução gradual do número de dígitos até chegar a 03 dígitos (COPE, 1887). Pertencem a essa ordem as famílias Tapiridae, representada pelas antas, família Rhinocerotidae, representada pelos rinocerontes e a Equidae, onde encontram-se os cavalos, jumentos e zebras (Orr, 1986; Quse, et al., 2014).

A família Tapiridae é formada por um único gênero, o Tapirus, onde são conhecidas cinco espécies; a Tapirus bairdii, com ocorrência na América Central, México e noroeste da América do Sul; Tapirus pinchaque, cuja ocorrência é andina na Colômbia, Equador e Peru; Tapirus indicus, que ocorre na Indonésia, Malásia, Tailândia e Burma; e Tapirus Terrestris que é encontrada em boa parte da América do Sul, desde a Venezuela até o nordeste da Argentina e Paraguai e Tapírus Kaboumani espécie identificada no norte da América do Sul no ano de 2013 (Medici, et al., 2007; Medici, et al., 2012; Cozzuol, et al., 2013; Pereira, et al., 2015; Pereira, et al., 2017).

A espécie Tapirus terrestris, também conhecida como anta brasileira, é o maior mamífero terrestre do Neotropico, desenvolve um papel fundamental na dispersão de sementes, forrageio de plantas, participação na reciclagem de nutrientes e como fornecedor de alimento para fauna coprófaga (Hickman, et al., 2009; Medici, 2011; Pereira, et al., 2015).

As antas podem ser responsáveis por manter padrões e processos ecológicos exclusivos de interações com as plantas que antes eram realizados por grandes herbívoros da megafauna, uma vez que as mesmas podem ser consideradas as últimas representantes dessa megafauna Pleistocênica nas Américas Central e do Sul (Bachand, et al., 2009; Quse, et al., 2014).

A espécie $T$. terrestris se encontra atualmente listada pela União Internacional para a Conservação da Natureza (IUCN - International Union for the Conservation of Nature) como "Vulnerável à Extinção" (IUCN, 2013; Pereira, et al., 2018). Segundo Ross. (2012); Quse, et al. (2014) e IUCN (2016) apresentam que isso ocorre devido a 
pressão de caça, perda e degradação de habitat natural que a espécie vem sofrendo.

Embora estudos acerca da motricidade dos ungulados sejam escassos, existe uma grande quantidade de especializações encontradas (Campbell, 1936). Dessa forma, com o intuito de fornecer mais dados anatômicos sobre a espécie, objetivou-se descrever os ossos e músculos da perna e pé de $T$. terrestris com ênfase nas origens, inserções e ações musculares.

\section{MATERIAIS E MÉTODOS}

Foram utilizados quatro exemplares de $T$. terrestris adultos (Linnaeus, 1978) adultos pertencentes ao acervo didático-científico do Laboratório de Ensino e Pesquisa em Animais Silvestres da Universidade Federal de Uberlândia (LAPAS-UFU). Os espécimes foram fixados em solução aquosa de formaldeído a 10\% (a partir da solução comercial a 37\%) e conservados em cubas opacas contendo a mesma solução.

Para a descrição óssea as peças anatômicas foram radiografadas, para posterior visualização da posição dos ossos, em seguida maceradas em água fervente e posteriormente colocadas em solução de peróxido de hidrogênio por 12 horas, para clareamento das peças. Depois de limpos e secos, os ossos foram identificados e minuciosamente descritos.

Já para a descrição muscular inicialmente foi feita a retirada da pele e do excesso de tecido adiposo, os músculos foram expostos e dissecados, segundo as técnicas usuais em anatomia macroscópica, identificados e descritos, observando-se a origem e inserção muscular.

As imagens foram registradas com câmera digital Nikon Coolpix L840 e as fotografias foram tratadas pelo software Photoshop CS (2012®). . As descrições, tanto óssea quanto muscular, foram baseadas e comparadas com dados existentes na literatura, sendo que a nomenclatura adotada para esta pesquisa está de acordo com o International Committee on Veterinary Gross Anatomical Nomenclature (2012), usando como padrão principal de comparação os equinos devido a sua proximidade taxonômica com a espécie. O procedimento foi aprovado pela Comissão de Ética na Utilização de Animais da Universidade Federal de Uberlândia, através do parecer $n^{\circ}$ 069/12 e pelo Instituto Chico Mendes de Conservação da Biodiversidade (ICMBio/SISBIO 49266-1) e pelo termo de cooperação 002/2011 IBAMA/UFU/LAPAS.

\section{RESULTADOS E DISCUSSÃO Ossos da perna}

A perna de Tapirus terrestris é composta pela tíbia e fíbula, sendo a tíbia o principal osso da perna e juntamente com a fíbula, constitui sua base óssea, conforme mostrado na Figura 1. A tíbia é mais curta que o fêmur e divide-se em extremidade proximal, corpo e extremidade distal. A extremidade proximal da tíbia é a porção mais larga do osso e exibe um aspecto triangular. Apresenta uma face articular constituída pelos côndilos medial e lateral, para articulação com os correspondentes côndilos da extremidade distal do fêmur (Varela, 2010).

O corpo da tíbia é dividido em quatro faces; cranial, caudal, medial e lateral. Na face cranial encontra-se a tuberosidade da tíbia. Na face caudal a região proximal é convexa com a presença de forames nutrícios; a face medial possui uma área convexa e rugosa; a face lateral, lisa e ligeiramente retorcida, forma juntamente com a fíbula o espaço interósse (Borges, et al., 2016; Borges, et al., 2000).

Em T. terrestris a extremidade distal é menor que a proximal e apresenta face articular com os ossos do tarso e um maléolo. A superfície para a articulação com os ossos do tarso é denominada cóclea da tíbia. O 
maléolo medial constitui a parede medial da cóclea e nesta encontra-se o sulco maleolar.

Figura 1. Fotografia dos ossos tíbia e fíbula de Tapirus Terrestris.

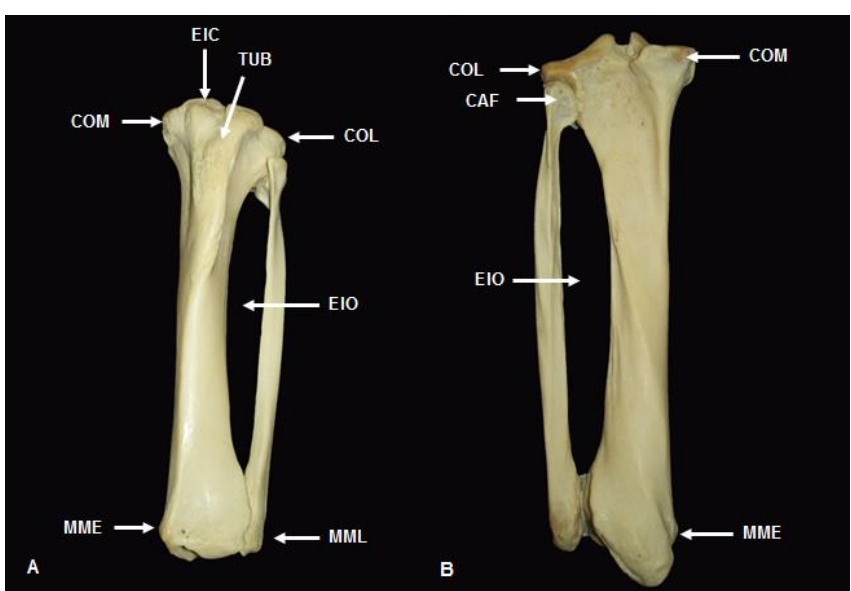

Legenda: (A), vista cranial; (B), vista caudal. TUB, tuberosidade da tíbia; COL, côndilo lateral; COM, côndilo medial; EIC, eminência intercondilar; MME, maléolo medial; MML, maléolo lateral; EIO, espaço interósseo; $\mathrm{CAF}$, cabeça da fíbula.

A fíbula é um osso longo com duas extremidades, proximal e distal (maleolar), que se localiza lateralmente à tíbia. Na extremidade proximal encontra-se a cabeça da fíbula, que se articula com o côndilo lateral da tíbia; e a extremidade distal se prolonga formando o maléolo lateral (Figura 1).

Segundo Getty (2013), em equinos a fíbula é um osso longo reduzido, situado na borda lateral da tíbia. Nesses animais o corpo da fíbula termina em ponta na metade do terço distal da borda lateral da tíbia, o que não condiz com os achados em $T$. terrestris, nos quais esse osso se assemelha mais aos carnívoros e aos suínos que, segundo König e Liebich (2016), apresentam a fíbula acompanhando toda a extensão da tíbia, corroborando com os achados, como observado na Figura 1. Em T. terrestris a tíbia e a fíbula encontram-se separadas por um espaço, como descrito por Oliveira, et al. (2009) em Dasyprocta azarae, onde a tíbia e a fíbula não são fundidas, sendo a fíbula bem delgada e equivalente em tamanho à tíbia.

\section{Ossos do Pé}

O esqueleto do pé de T. terrestris é composto por três partes similares (análogas) à mão; sendo tarso, metatarso e dedos. O tarso é constituído por sete ossos conforme apresentado nas Figuras 2 e 3, que estão dispostos em duas fileiras, sendo estas; distal e proximal, em concordância com os achados de Oliveira, et al. (2007) e Oliveira, et al. (2009), em Agouti paca e Dasyprocta azarae, respectivamente. Os ossos dessas fileiras são todos irregulares.

Em T. terrestris o tálus é caracterizado por um corpo compacto. A tróclea do tálus articula-se com a cóclea da tíbia. Em sua face distal apresenta a tróclea distal articulando-se com o osso central do tarso.

Figura 2. Fotografia dos ossos do pé de Tapirus Terrestris.

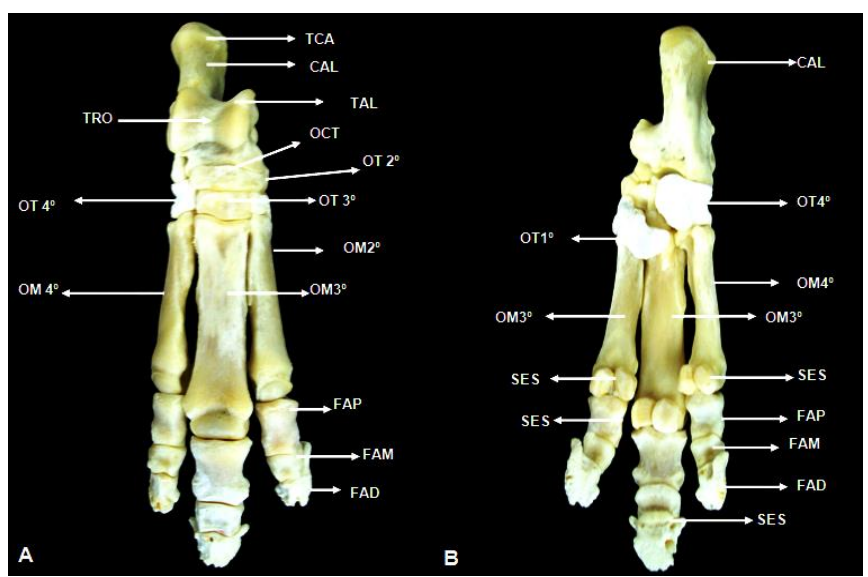

Legenda: (A), vista dorsal; (B), vista plantar. TAL, tálus; CAL, calcâneo; OCT, osso central do tarso; $\mathrm{OT}^{\circ}$, osso tarsal I; $\mathrm{OT}^{\circ}$, osso tarsal II; $\mathrm{OT}^{\circ}$, osso tarsal III; $\mathrm{OT}^{\circ}$, osso tarsal IV; $\mathrm{OM}^{\circ}$, osso metatársico II; $\mathrm{OM}^{\circ}$, osso metatársico III; $\mathrm{OM} 4^{\circ}$, osso metatársico IV; FAP, falange proximal; FAM, falange média; FAD, falange distal; TCA, tuberosidade calcânea; SES, ossos sesamoides; TRO, tróclea.

O calcâneo de T. terrestris, assim como apresentado por Varela (2010) em Ozotoceros bezoarticus, localiza-se na face lateroplantar do tálus, articulando-se com este. Na face lateral do tálus e face medial do calcâneo localiza-se o espaço denominado seio do tarso. Na região proximal do calcâneo localiza- 
se a tuberosidade do calcâneo. Do corpo do calcâneo sobressai-se a projeção óssea para articulação com o tálus, em sua face medial, denominada sustentáculo talar. A face plantar do sustentáculo talar forma com o corpo do calcâneo o sulco do calcâneo. A face lateral do calcâneo articula-se com o osso tarsal quarto.

Nas antas o osso central do tarso articula-se proximalmente com o tálus, distalmente com o osso tarsal terceiro (intermédio), lateralmente com o tarsal quarto e medialmente com o tarsal segundo. O osso tarsal quarto articula-se proximalmente com o calcâneo e com o tálus, medialmente com o osso central do tarso e com o osso tarsal terceiro (intermédio) e distalmente com o osso metatársico IV (lateral).

O osso tarsal terceiro está proximalmente articulado com o osso central do tarso, distalmente com o metatársico III, medialmente com o tarsal segundo e metatársico II e lateralmente com o osso tarsal quarto. $\mathrm{O}$ osso tarsal segundo proximalmente se articula com o osso central do tarso, lateralmente com o osso tarsal terceiro, distalmente com o metatársico II e medialmente com o osso tarsal primeiro.

Em T. terrestris os ossos metatársicos são três (Figura 2) semelhante aos achados de Oliveira, et al. (2009) em Dasyprocta azarae, sendo denominados de medial para lateral como; metatarso II, III e IV. O osso metatársico III é o intermédio, sendo este mais longo, e o II e IV são de tamanho semelhante e menos longos que o terceiro.

O osso metatársico II é longo, com duas extremidades articulares, proximal e distal, e corpo, sendo aproximadamente triangular. $\mathrm{Na}$ região proximal, este se articula com os ossos társicos I e II. Em sua face lateral há a presença de uma pequena protuberância e sua região distal articula-se com a falange proximal do dedo II.

O osso metatársico III é o maior dos três; sendo longo, com duas extremidades articulares, proximal e distal, e corpo; é aproximadamente retangular com quatro faces; dorsal, plantar, lateral e medial. A extremidade articular proximal é triangular e relaciona-se com o osso tarsal III e a extremidade distal é arredondada e articula-se com a falange proximal do dedo III.

Figura 3. Radiografia dos ossos do pé de Tapirus terrestris.

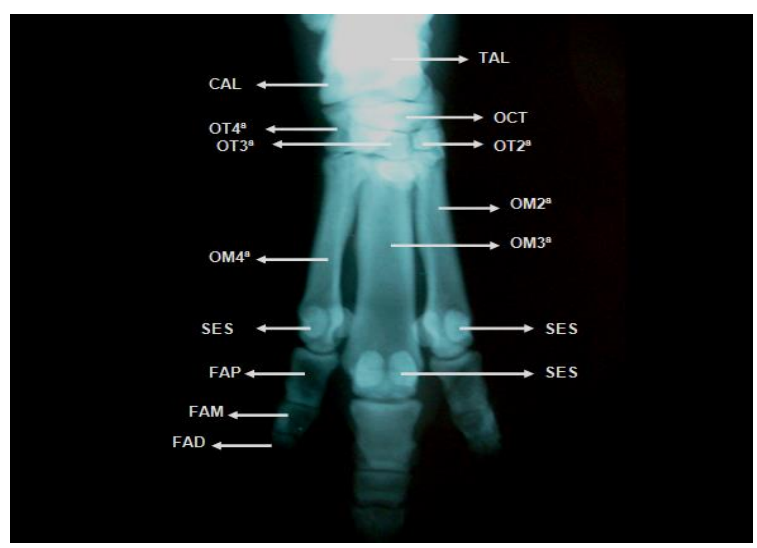

Legenda: TAL, talus; CAL, calcâneo; OCT, osso central do tarso; $\mathrm{OT}^{\circ}$, osso tarsal II; $\mathrm{OT}^{\circ}$, osso tarsal III; OT4 ${ }^{\circ}$, osso tarsal IV; $\mathrm{OM}^{\circ}$, osso metatársico II; $\mathrm{OM}^{\circ}$, osso metatársico III; $\mathrm{OM} 4^{\circ}$, osso metatársico IV; SES, ossos sesamoides; FAP, falange proximal; FAM, falange média; FAD, falange distal.

O osso metatársico IV é longo, com duas extremidades articulares, proximal e distal, e corpo, sendo aproximadamente triangular, com três faces; plantar, dorsal e medial. Na região proximal, este se articula com o osso tarsal IV e na região distal articulase com a falange proximal do dedo IV.

No pé de T. terrestris são evidenciados três dígitos com três falanges em cada, sendo elas, proximal, média e distal, somando um total de nove falanges e sesamoides, conforme apresentado na Figura 2, corroborando os achados de Oliveira, et al. (2009) em Dasyprocta azarae. A presença de três dígitos é uma das adaptações morfológicas que enquadram os $T$. terrestris na ordem Perissodactyla, onde todos os indivíduos apresentam dedos ímpares, com cascos córneos em todos os dedos, como apresentado pela espécie (Hickman, et al., 2009). Em 
T. Terrestris, assim como nos demais ungulados, os dedos do pé são mais fortemente virados para o exterior (lateral) do que os dedos da mão, conforme descrito por Cope (1887).

\section{Músculos da perna e pé}

Os músculos da perna e pé de T. terrestris são gastrocnêmio, flexor digital lateral, extensor digital lateral, extensor digital longo, fibular terceiro, extensor digital curto, flexor digital superficial, tibial cranial, flexor digital, tibial caudal, poplíteo, interósseos e lumbricais, eles se originam-se no fêmur, tíbia e fíbula e se inserem nas superfícies da tíbia, fíbula, tarso, metatarso e falanges, conforme mostra a Figura 4.

O músculo fibular terceiro situa-se entre o músculo extensor digital longo e músculo tibial cranial; origina-se na fossa extensora do fêmur juntamente com o músculo extensor digital longo e insere-se na extremidade proximal do osso tarsal III e IV e calcâneo; diferindo do equino onde, segundo Getty (2013), ele insere-se no terceiro osso tarsal e terceiro metatársico. No equino ele se comporta como elemento tensor no mecanismo de sustentação dos membros pelvinos (König e Liebich, 2016).

Em T. terrestris o músculo extensor digital longo é um músculo longo que se origina junto ao músculo fibular terceiro na fossa extensora do epicôndilo lateral do fêmur, situando-se superficialmente na tíbia similar aos achados de Varela (2010) em Ozotoceros bezoarticus. Como em $T$. terrestris o músculo possui pontos de origem e inserção similares ao Ozotoceros bezoarticus (Varela, 2010) e ao equino (Getty, 2013), pode-se sugerir que tenha a mesma função de extensor do dedo e da articulação do joelho proposta pelos autores.

O músculo tibial cranial situa-se na face craniolateral da tíbia, entre o músculo extensor digital longo e o músculo tibial cranial, sendo um músculo achatado e largo proximalmente e estreito distalmente conforme apresentado na Figura 4. Origina-se no côndilo lateral e borda da tíbia e insere-se no osso tarsal I e tendão do fibular $3^{\circ}$, possuindo os mesmos pontos de origem dos equinos com diferenciação no ponto de inserção, nos quais, segundo Getty (2013) e Dyce, et al. (2010) possui um dos pontos de inserção no osso metatársico terceiro, não apresentado pelos $T$. Terrestris.

Figura 4. Fotografia dos músculos da perna e pé de Tapirus Terrestris

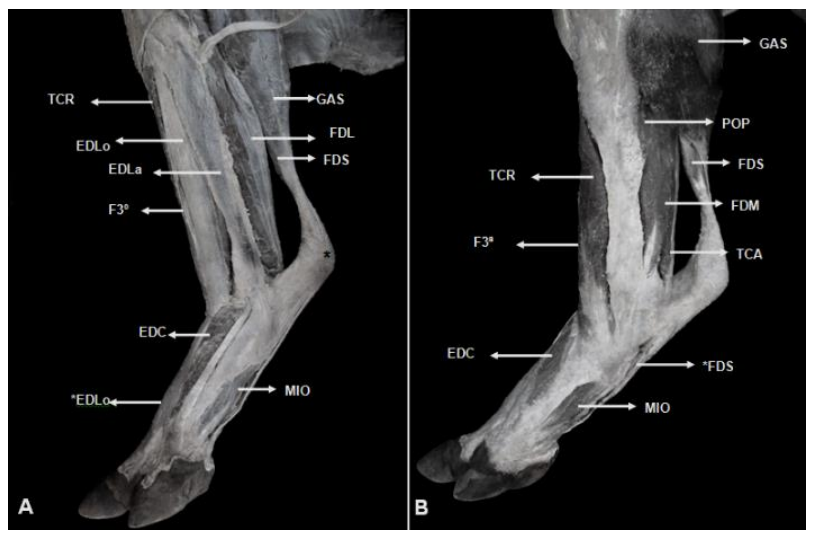

Legenda: (A), vista lateral; (B), vista medial. GAS, m. gastrocnêmio; FDL, m. flexor digital lateral; EDLa, m. extensor digital lateral; EDLo, m. extensor digital longo; $\mathrm{F}^{\circ}$, m. fibular terceiro; $\mathrm{EDC}, \mathrm{m}$. extensor digital curto; FDS, m. flexor digital superficial; TCR, m. tibial cranial; *EDLo, tendão do m. extensor digital longo; *FDS, cobertura calcânea do músculo flexor digital superficial; FDM, m. flexor digital medial; TCA, m. tibial caudal; POP, m. poplíteo; MIO, mm. interósseos; *, tendão do músculo flexor digital superficial.

O músculo extensor digital lateral situa-se na superfície lateral da perna, caudal ao m. extensor digital longo. Tem sua origem na fíbula, côndilo lateral e borda lateral da tíbia e espaço interósseo, apresentando o mesmo padrão nos equinos (Getty, 2013).

Apesar da anta não possuir o dedo I ela apresenta unido com o músculo tibial caudal um músculo com características semelhantes ao músculo flexor do dedo I de forma similar aos equinos (König e Liebich, 2016). Esse músculo se apresenta de forma 
totalmente independente somente nos carnívoros, suínos e ovinos.

A denominação de músculo tríceps sural é um termo usado para o músculo gastrocnêmio e o músculo sóleo. Em T. terrestris o músculo gastrocnêmio é um músculo forte e fusiforme que possui duas cabeças, uma lateral e outra medial, originando-se proximalmente aos côndilos do fêmur. O músculo sóleo em $T$. terrestris é um músculo pequeno que se origina na cabeça da fíbula e une-se em sentido caudal a cabeça lateral do músculo gastrocnêmio. Em alguns animais, como os carnívoros (Getty, 2013), esse músculo se encontra ausente, assim como em Procyon cancrivorus (Pereira, et al., 2010). $\mathrm{O}$ tendão do $\mathrm{m}$. sóleo une-se ao tendão do $\mathrm{m}$. gastrocnêmio formando um tendão comum, o tendão calcanear, que se insere no calcâneo, possuindo os mesmos padrões de origem e inserção apresentados pelos equinos (Getty, 2013) e pelo Ozotoceros bezoarticus, conforme os achados de Varela (2010). E para outros mamíferos como encontrado por (Ribeiro et. al., 2016).

O músculo flexor digital superficial, em $T$. terrestris, situa-se sob a cobertura das duas cabeças do músculo gastrocnêmio. Tem sua origem na fossa supracondilar do fêmur. Seu tendão é localizado profundamente e se entende na altura da tíbia em sentido plantar expandindo-se sobre o tendão calcanear na tuberosidade calcânea. Possui a mesma origem e inserção apresentada pelos equinos (Getty, 2013; König e Liebich, 2016).

O músculo flexor digital profundo é composto por três cabeças independentes que formam os músculos tibial caudal, flexor digital lateral e flexor digital medial; essas três cabeças originam-se na tíbia e fíbula. Sua inserção ocorre na área flexora das falanges distais do mesmo modo como ocorre nos equinos (Getty, 2013). As expansões em T. terrestris somam três, enquanto nos suínos são quatro, nos ruminantes duas e nos equinos uma, conforme descrito por König e Liebich (2016). A parte caudal forma o músculo tibial caudal, que se situa entre o músculo flexor digital medial e o flexor digital lateral; está intimamente ligada com o músculo flexor digital lateral. A porção medial forma o músculo flexor digital medial, que se situa entre o músculo digital lateral e o músculo poplíteo. A porção lateral forma o músculo flexor digital lateral, que se situa entre o músculo extensor digital lateral e o músculo tibial caudal, tem sua origem no côndilo lateral e na superfície caudal da tíbia.

Nas antas o músculo poplíteo é um músculo triangular e achatado, que se situa na face profunda do músculo gastrocnêmio. Sua origem ocorre no côndilo lateral do fêmur e na fossa poplítea; e sua inserção no terço proximal da superfície caudal da tíbia, próximo à linha poplítea; apresentando o mesmo padrão de origem e inserção descrito em Procyon cancrivorus (Pereira, et al., 2010).

O músculo extensor digital curto em $T$. terrestris situa-se sobre o metatarso, originando-se no tendão lateral do músculo fibular terceiro e inserindose nos músculos extensor digital longo e extensor digital lateral. É um músculo pouco desenvolvido, assim como apresentado pelos equinos e ruminantes (König e Liebich, 2016).

Nos T. terrestris os músculos interósseos são compostos por três músculos; medial, intermédio e lateral, cada um surgindo do osso metatársico correspondente. Segundo Schwarzbach et al. (2008); Getty (2013), o equino, um Perissodactyla assim como a anta, também apresenta três músculos distribuídos da mesma forma.

Os músculos lumbricais são fusiformes, musculosos e se originam de delgados feixes dos tendões do músculo flexor digital profundo; sua inserção é nas falanges proximais dos dedos II, III e IV conforme apresentado no quadro 1. Segundo König e 
Liebich (2016) nos suínos e carnívoros ele é um músculo inteiramente volumoso já nos equinos é um músculo tendíneo, diferentemente do que ocorre em $T$. terrestris, que, embora apresentem essa diferença, apresentam o mesmo padrão de distribuição encontrado nos equinos conforme descrito pelos autores.
Os pontos de fixação e a inferência da ação dos músculos que compõem a perna e pé da anta estão apresentados no Quadro 1. As Figuras 5, 6 e 7 mostram os pontos de origem e inserção dos músculos em questão nos ossos do membro pelvino de T. terrestris.

Quadro 1 - Pontos de fixação e inferência da ação dos músculos da perna e pé de Tapirus terrestris.

\begin{tabular}{|c|c|c|c|}
\hline MÚSCULO & ORIGEM & INSERÇÃO & INFERÊNCIA DA AÇÃO \\
\hline $\begin{array}{l}\text { Músculo fibular } \\
\text { terceiro. }\end{array}$ & Fossa extensora do fêmur. & $\begin{array}{l}\text { Extremidade proximal dos ossos tarsais III e IV } \\
\text { e calcâneo. }\end{array}$ & $\begin{array}{l}\text { Flexor do tarso e extensor do } \\
\text { joelho. }\end{array}$ \\
\hline $\begin{array}{l}\text { Músculo extensor } \\
\text { digital longo. }\end{array}$ & Fossa extensora do fêmur. & $\begin{array}{l}\text { Superfície dorsal das extremidades proximal das } \\
\text { falanges proximal, média e distal dos dedos } \\
\text { II,III e IV. }\end{array}$ & $\begin{array}{l}\text { Extensor dos dedos II, III e IV e } \\
\text { do joelho. }\end{array}$ \\
\hline $\begin{array}{l}\text { Músculo tibial } \\
\text { cranial. }\end{array}$ & $\begin{array}{l}\text { Côndilo lateral e borda lateral da tíbia e } \\
\text { fáscia crural. }\end{array}$ & Osso tarsal I, tendão do m. fibular terceiro. & Flexor do tarso. \\
\hline $\begin{array}{l}\text { Músculo extensor } \\
\text { digital lateral. }\end{array}$ & $\begin{array}{l}\text { Borda medial da Fíbula, côndilo lateral } \\
\text { e borda lateral da tíbia, espaço } \\
\text { interósseo. }\end{array}$ & $\begin{array}{l}\text { Extremidade proximal do osso metatársico IV e } \\
\text { suas } \\
\text { falanges média e distal. }\end{array}$ & Extensor do dedo IV. \\
\hline $\begin{array}{l}\text { Músculo flexor do } \\
\text { dedo I. }\end{array}$ & $\begin{array}{l}\text { Côndilo lateral da tíbia e terço proximal } \\
\text { da fíbula comum ao tibial caudal. }\end{array}$ & $\begin{array}{l}\text { Tendão do flexor profundo e falange distal dos } \\
\text { dedos II, III, IV comum ao tibial caudal. }\end{array}$ & $\begin{array}{l}\text { Flexor dos dedos II, III, IV } \\
\text { juntamente com o tibial caudal. }\end{array}$ \\
\hline $\begin{array}{l}\text { Músculo } \\
\text { gastrocnêmio. }\end{array}$ & Terço distal da face caudal do fêmur. & Tuberosidade calcânea. & $\begin{array}{l}\text { Extensor do tarso e flexor do } \\
\text { joelho. }\end{array}$ \\
\hline Músculo sóleo. & Cabeça da fíbula. & Tendão calcanear. & Extensor do tarso. \\
\hline $\begin{array}{l}\text { Músculo tibial } \\
\text { caudal. }\end{array}$ & $\begin{array}{l}\text { condilo lateral da tíbia e terço proximal } \\
\text { da fíbula. }\end{array}$ & $\begin{array}{l}\text { Tendão do flexor profundo e falange distal dos } \\
\text { dedos II, III, IV. }\end{array}$ & Flexor dos dedos II, III, IV. \\
\hline $\begin{array}{l}\text { Músculo flexor } \\
\text { digital medial. }\end{array}$ & Cabeça da fíbula. & $\begin{array}{l}\text { Tendão do m. flexor profundo e falange distal } \\
\text { dos dedos II, III, IV. }\end{array}$ & Flexor dos dedos II, III, IV. \\
\hline $\begin{array}{l}\text { Músculo flexor } \\
\text { digital lateral. }\end{array}$ & $\begin{array}{l}\text { Côndilo lateral e superfície caudal da } \\
\text { tíbia. }\end{array}$ & $\begin{array}{l}\text { Tendão do m. flexor profundo e falange distal } \\
\text { dos dedos II, III e IV. }\end{array}$ & Flexor dos dedos II, III, IV. \\
\hline Músculo poplíteo. & Epicôndilo lateral do fêmur. & Superfície caudal terço distal da tíbia. & Flexor do joelho. \\
\hline $\begin{array}{l}\text { Músculo extensor } \\
\text { digital curto. }\end{array}$ & Tendão lateral do m. fibular terceiro. & $\begin{array}{l}\text { Tendão do m. extensor digital longo e extensor } \\
\text { digital lateral. }\end{array}$ & $\begin{array}{l}\text { Auxiliar o extensor digital } \\
\text { longo. }\end{array}$ \\
\hline $\begin{array}{l}\text { Músculos } \\
\text { interósseos. }\end{array}$ & Ossos metatársicos II, III, IV. & $\begin{array}{l}\text { Extremidade distal dos ossos metatársicos II, III, } \\
\text { IV e sesamoides. }\end{array}$ & Fixar a articulação falangeana. \\
\hline Músculos lumbricais. & Tendão do m. flexor digital profundo. & Falange proximal dos dedos II, III e IV. & Tensionar os mm. flexores. \\
\hline
\end{tabular}


Figura 5 - Fotografia do osso fêmur de $T$. terrestris, vista caudal. Origem dos músculos da perna e pé.

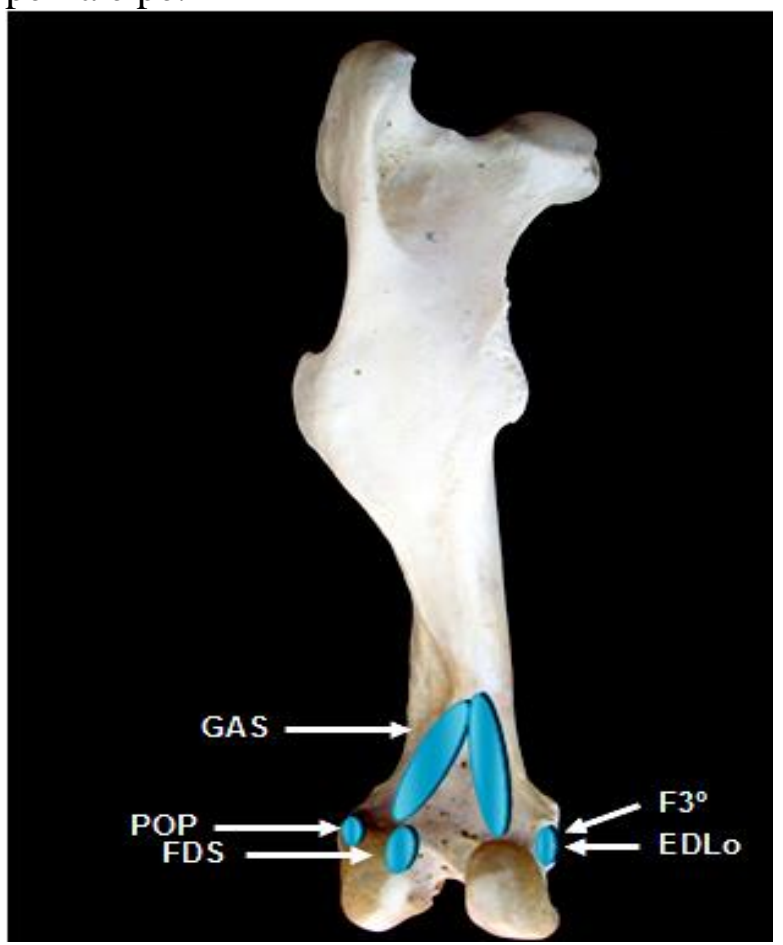

Legenda: POP, m. poplíteo; GAS, m. gastrocnêmio; FDS, m. flexor digital superficial; EDLo, m. extensor digital longo; $\mathrm{F}^{\circ}$, m. fibular terceiro.

Figura 6 - Fotografia dos ossos tíbia e fíbula de Tapirus Terrestris. Origens (azul) e inserção (roxo) dos músculos da perna e pé.

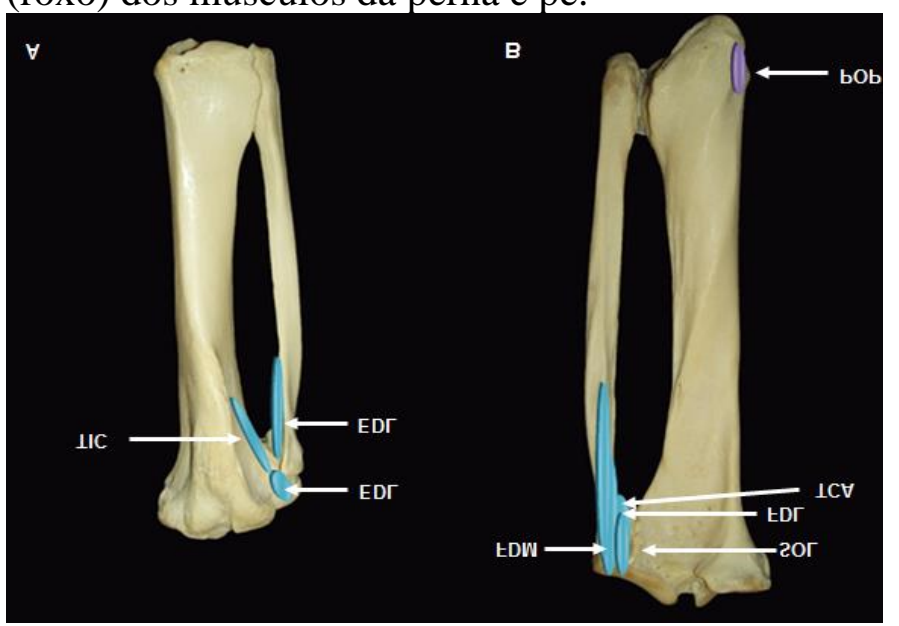

Legenda: (A), vista cranial; (B), vista caudal. TIC, m. tibial cranial; EDL, m. extensor digital lateral; FDL, m. flexor digital lateral; TCA, m. tibial caudal; POP, m. poplíteo; SOL, m. sóleo; FDM, m. flexor digital medial.
Figura 7 - Fotografia dos ossos do pé de Tapirus Terrestris. Inserções dos músculos da perna e pé.

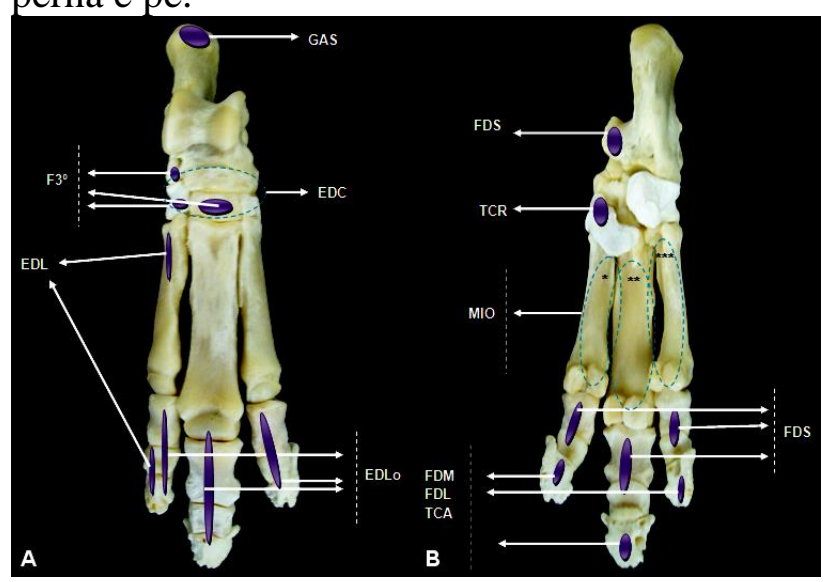

Legenda: (A), vista dorsal; (B), vista plantar. GAS, m. gastrocnêmio; $\mathrm{F}^{\circ}$, m. fibular terceiro; EDL, m. extensor digital lateral; EDLo, m. extensor digital longo; EDC, m. extensor digital curto; FDS, m. flexor digital superficial; TCA, m. tibial caudal; FDM, m. flexor digital medial; FDL, m. flexor digital lateral; TIC, m. tibial cranial; MIO, mm. interósseos, * medial, ** intermédio, $* * *$ lateral.

\section{CONCLUSÃO}

Os Tapirus terrestris possuem características osteológicas e musculares da perna e pé semelhantes a dos equinos, bem como dos animais silvestres a que foram comparadas, entretanto, algumas diferenças morfológicas podem ser evidenciadas tais como o número de dígitos, três expansões no músculo flexor digital profundo, o músculo tibial cranial e fibular terceiro apresentam diferenciação no ponto de inserção quando comparados com os equinos.

Todos os autores declararam não haver qualquer potencial conflito de interesses referente a este artigo.

\section{REFERÊNCIAS}

ASSOCIAÇÃO BRASILEIRA DE NORMAS TÉCNICAS. NBR 14724: informação e documentação: trabalhos acadêmicos: apresentação. Rio de Janeiro, 2011. 
Bachand, M. et al. Frugivoria por Tapirus terrestris em três regiões do Pantanal, Brasil. R. Bras. Bioci, 2 (7): 188-194, 2009.

CAMPBELL, B. Comparative Myology of the Forelimb of the Hippopotamus, Pig and Tapir. Teid American Jownal or Anatomy, 59 (2): 01-10, 1936.

BORGES, D.C.S. SANTOS, A.L.Q; PEREIRA, S.G.; PEREIRA, W.A.; PEREIRA, R.A. Características adaptativas do membro pelvino de Tapirus terrestris (Perissodactyla, Taperidae). ALTUS CIÊNCIA: Revista Acadêmica Multidisciplinar da Faculdade Cidade de João Pinheiro, 6 (04): 05-15. 2016.

BORGES, D.C.S. et al. ANTA BRASILEIRA - Tapirus terrestris: características gerais, mitológicas e seu conhecimento popular nas regiões do Noroeste e do Alto Paranaíba em Minas Gerais. Revista de Pesquisa Interdisciplinar, 5 (01): 289-315. 2020.

COPE, E.D. The Perissodactyla. The American Naturalist, 21 (11): 985-1007, 1887.

CULLEN, Jr. L., BODMER, R.E., PADUA, C.V. Effects of hunting in habitat fragments of the Atlantic forests, Brazil. Biol Conserv, 95 (01): 49 - 56, 2000.

DYCE，K.M.; SACK，M. O.; WENSING，C.J.G. Tratado de anatomia veterinária. 4. ed. Rio de Janeiro: Elsevier, 2010.

GETTY, R. Anatomia dos animais domésticos. $5^{\text {a }}$ Edição. Rio de Janeiro: Ed Guanabara Koogan. 2013. $2000 \mathrm{p}$

HICKMAN JR., C.P.; ROBERTS, L.S.; LARSON, A. Princípios Integrados de Zoologia, $11^{\mathrm{a}}$ ed., Rio de Janeiro: Ed. Guanabara Kogan, 2009.

HOLANDA, EC. et al. New Tapirus species (Mammalia: Perissodactyla: Tapiridae) from the upper Pleistocene of Amazonia, Brazil. Journal of Mammalogy, 92 (10). 111-20, 2011.

INTERNATIONAL COMMITTEE ON VETERINARY GROSS ANATOMICAL NOMENCLATURE. Nomina anatomica veterinária. 5. ed. (rev.) Knoxville: World Association on Veterinary Anatomist, 2012. 177 p.

IUCN. 2013. IUCN Red List of Threatened Species. Version 2016.1. Disponível em: <www.iucnredlist.org>. Acesso em: 03 nov. 2017.

KÖNIG, H; LIEBICH, H.G. Anatomia dos Animais Domésticos: Texto e Atlas Colorido. 6. ed. Porto Alegre: Artmed. 2016. 800 p.
MEDICI, E.P. Family Tapiridae (Tapirs). In: WILSON, D.E; MITTERMEIER, R,A. Handbook of the mammals of the world - Volume 2: Hoofed Mammals. Barcelona: Lynx Edicions; 2011. 886p. Disponível em:

https://www.lynxeds.com/hmw/handbook-mammalsworld-volume-2>. Acesso em 01 de junho 2017.

MEDICI, E.P.; et al. Workshop para a Conservação da Anta Brasileira: Relatório Final. IUCN/SSC Tapir Specialist Group (TSG) \& IUCN/SSC Conservation Breeding Specialist Group (CBSG), Brasil. 2007

OLIVEIRA F.S.; CANOLA J.C.; MACHADO M.R.F.; CAMARGO M.H.B. Descrição anátomoradiográfica do esqueleto apendicular da paca (Agouti paca). Acta Scientiae Veterinariae, 7 (7): 83-87, 2007.

OLIVEIRA, F.S.; MARTINS, L.L.; PAULONI, A.P.; TONIOLLO, G.H.; CANOLA, J.C.; MACHADO, M.R.F. Descrição anátomo-radiográfica do esqueleto apendicular da cutia (Dasyprocta azarae, Lichtenstein, 1823). Ars veterinária, 25 (1): . 28-31, 2009.

ORR, R. T. Biologia dos Vetebrados. $5^{\text {a }}$.ed. São Paulo: Roca, 1986.

ROOS, A. A Biodiversidade E A Extinção Das Espécies. Rev. Elet. em Gestão, Educação e Tecnologia Ambiental, 7 (7): 1494-1499, 2012.

PAULO-COUTO, C. de. , Tratado de Paleomastozoologia. Rio de Janeiro. Academia Brasileira de Ciências, 1979.

PEREIRA, F.C.; LIMA, V.M.; PEREIRA, K.F. Descrição anatômica dos músculos da perna de Procyon cancrivorus (Cuvier 1798). Biotemas, 23 (3): 159-165 2010.

PEREIRA, S.G. SANTOS, A.L.Q. BORGES, D.C.S. RIBEIRO, P.R.Q.; RODRIGUES, R. Anatomia Óssea E Muscular Do Cíngulo Escapular E Braço De Tapirus terrestris (Perissodactyla: Tapiridae). Ciênc. anim. Bras., 16 (2): 145-155. 2015

PEREIRA, U.D.; HOSSOTANI, C.M.S.; SILVA, H. L. Tecnologias Reprodutivas Com Potencial $\mathrm{Na}$ Conservação De Tapirus terrestris Linnaeus, 1758. Revista Saúde e Meio Ambiente - RESMA, 7 (2): 82-91, 2018.

RIBEIRO, P. R. Q. et al., Movement anatomy of the gluteal region and thigh of the giant anteater Myrmecophaga 
(Myrmecophagidae: Pilosa). Pesq. Vet. Bras., 36 (6): 25-35, 2016.

SCHWARZBACH, S.V.; PAGLIOSA, G.M.; ROSCOE, M.P.; ALVES, G.E.S. Ligamento suspensório da articulação metacarpo/metatarso falangianas nos eqüinos: aspectos evolutivos, anatômicos, histofisiológicos e das afecções. Ciência Rural, 38 (4): 1193-1198, 2008.
VARELA, G. Osteología y miología de lós miembros anterior e posterior del venado de campo (Ozotoceros bezoarticus). 2010. 51 f. Tesina (Licenciatura en Ciencias Biológicas) - Universidad de La República Uruguay, Uruguay, 2010. 